\title{
Association of Boron, Copper, Germanium, Magnesium, Selenium and Zinc with Incidence of Rheumatoid Arthritis
}

\author{
Shatha Rouf Moustafa ${ }^{1,}$, Namir Al-Taweel ${ }^{2}$, Fadhil Mohsen ${ }^{3}$ \\ ${ }^{1}$ Clinical Analysis Department, College of Pharmacy, Hawler Medical University, Havalan city, Erbil, Iraq, Arabian \\ ${ }^{2}$ Community Medicine Department, College of Medicine, Hawler Medical University, Performing the Statistical Study, Aeen Kawa city, \\ Erbil, Iraq Arabian \\ ${ }^{3}$ Ministry of Science and Technology/Chemistry Research Department, Karada city, Baghdad, Iraq, Arabian
}

\section{Email address:}

shatha003@yahoo.com (S. R. Moustafa),namiraltawil@yahoo.com (N. Al-Taweel), fadhilabid2004@yahoo.com (F. Mohsen)

\section{To cite this article:}

Shatha Rouf Moustafa, Namir Al-Taweel, Fadhil Mohsen. Association of Boron, Copper, Germanium, Magnesium, Selenium and Zinc with Incidence of Rheumatoid Arthritis. American Journal of Internal Medicine. Vol. 3, No. 3, 2015, pp. 132-140.

doi: $10.11648 /$ j.ajim.20150303.17

\begin{abstract}
Background and Objectives: Trace elements have an important role in numerous metabolic processes. This study aimed to investigate the association between the levels of boron, copper, germanium, magnesium, selenium and zinc with the incidence of rheumatoid arthritis, and assess their relationship with other confounding factors, such as age, gender and type of rheumatoid arthritis (rheumatoid arthritis with rheumatoid factor positive or negative). This study also aimed to evaluate the correlation coefficient between all studied parameters. Methods: This case-control study was conducted on 56 men and women Iraqi patients with rheumatoid arthritis. An equal number of apparently healthy adults were also enrolled in this study as the control group. The patients were free from any diseases except rheumatoid arthritis, which was confirmed by clinical examination and laboratory estimations of biochemical and hematological tests. Serum levels of the investigated parameters were estimated using flame and flameless atomic absorption spectrophotometry. Results: Results showed that the serum levels of the investigated parameters significantly reduced in the patient groups compared with the control group. No significant age differences were observed in relation to the investigated parameters. In terms of the levels of boron, copper, magnesium and selenium a significant differences were observed between men and women. By contrast, no significant differences were observed between men and women in terms of the levels of germanium and zinc. Conclusion: The serum levels of the investigated elements were significantly reduced in patients with rheumatoid arthritis. Thus, supplementation with trace elements could be necessary for rheumatoid arthritis therapy, and even more important to individuals who are at high risk of developing rheumatoid arthritis. These findings prove the possible association between decreased serum levels of the studied parameters with the incidence of rheumatoid arthritis. Therefore, the estimation of these trace elements could be a useful complementary non-invasive diagnostic tool to determine trace elements status for early diagnosis and therapy of rheumatoid arthritis.
\end{abstract}

Keywords: Rheumatoid Arthritis, Boron, Copper, Germanium, Magnesium, Selenium, Zinc

\section{Introduction}

Rheumatoid arthritis (RA) is a systemic autoimmune disease characterized by chronic articular inflammation and progressive joint destruction that releases most prominent manifestations in the diarthrodial joints [1]. The shift toward the oxidant / antioxidant imbalance favors lipid peroxidation, which can lead to tissue damage [2]. Trace elements (TEs) are involved in many important processes associated with health, structural support, contraction of muscle, enzyme / hormone release, nerve conduction, and maintenance of mineral balance in the human body [3]. The importance of TEs in RA is of great interest because many TEs are cofactors in metabolic processes involving collagen and bone structure or immune system functions. Increased levels of cytokines, such as interleukin-1 (IL-1), tumor necrosis factor$\alpha(\mathrm{TNF}-\alpha)$, and IL- 6 , are associated with active RA, which may affect the bioavailability of these TEs by stimulating the production of metal-binding proteins in the liver or intestine.

The increased production of metallothionein may affect the 
sequestration of metal ions so that they are unavailable in blood circulation. Many of these TEs are incorporated into antioxidant enzymes. Elevated production of free radicals (FRs) in inflamed joints and dysfunction of the antioxidant system have been implicated in RA [4]. Inflammation and tissue damage associated with oxidative stress (OS) have also been implicated in the pathogenesis of RA [5].

Trace elements may play a role in the initiation, progression, and cure of the disease, as investigated by supplying different TEs to decrease pain and increase joint mobility [6].

\subsection{Boron}

Boron (B) is either directly related to immune defense mechanisms or indirectly affects components of the immune system [7]. Dietary boron affects the function of many metabolic enzymes, metabolism of steroid hormones, metabolism and utilization of several micronutrients, including calcium, magnesium, vitamin D [8], copper, nitrogen, triglycerides, glucose, and estrogen.

Boron controls the inflammatory process in arthritic conditions by down regulating the number of proinflammatory mediators and specific enzymatic activities typically elevated during inflammation at the inflammatory site [9]. Boron also inhibits inflammatory stress [10] and the production of inflammatory cytokines via cartilage cells and cells involved in inflammatory reactions [11]. The beneficial functions of boron include bone growth, brain development, inflammation, hormone function [12], arthritis alleviation or risk reduction, OS modulation, central nervous system function, maintenance and cancer risk reduction.

The mechanism of action for boron may be presented through steroid hormones, adhesion molecules, metabolic regulation, antitumor metabolites, and cell proliferation. The physiological concentration of boron can prevent the onset of and ameliorate collagen-induced arthritis.

\subsection{Copper}

Copper $(\mathrm{Cu})$ is a main component of metalloenzymes, which are necessary for connective tissue synthesis, catecholamine biosynthesis, carbohydrate metabolism, hemoglobin formation, collagen cross-linking, elastin, and hair keratin. Copper is also necessary for antioxidant enzymes to reduce reactive oxygen species. Copper is responsible for cartilage mineralization, formation of elastin and collagen structure [13], and collagen cross-linking [14].

\subsection{Germanium}

The most important characteristic of germanium $(\mathrm{Ge})$ is its ability to relieve pain by inhibiting the enzyme that inhibits the production of body endorphins [15]. Germanium can activate the immune system by increasing interferon generation, making it an immune stimulant. Germanium enhances cellular energy production by raising the cell's oxygen supply, supplements the tissue with oxygen by linking itself to oxygen to improve oxygenation of the tissue, and inhibits RA. The body requires more oxygen to support immune functions and help the body excrete toxins. Germanium may act on arthritis by modifying macrophage functions, which are associated with inflammation and immune regulation. The inhibition of IL-1 generation within the inflamed joint leads to the reduction of local inflammation and tissue damage. It decreases the peroxidation of fatty acids. Germanium plays an important role in free radical pathology.

\subsection{Magnesium}

Magnesium $(\mathrm{Mg})$ is associated with at least 300 enzymatic reactions, it participates in biochemical processes that involve the bone, such as bone metabolism and osteoporosis [16], bone structure and good health, conversion of vitamin $\mathrm{D}$ to its biologically active form 1,25-dihydroxy cholecalciferol, and genomic stability.

\subsection{Selenium}

Selenium ( $\mathrm{Se}$ ) is the main constituent of the antioxidant enzyme glutathione peroxidase. Thus, selenium is an important in pathological oxidative conditions, including RA [1]. Selenium produces anti-inflammatory, antiproliferative, and immune-altering effects. Dietary selenium supplementation potentially influences inflammation and immune responses [17]. Selenium is associated with numerous biochemical pathways related to RA. Therefore, selenium deficiency is associated with increased risk of RA.

\subsection{Zinc}

Zinc $(\mathrm{Zn})$ is an important for the proper functioning of more than 300 hormones and enzymes in the human body. These hormones and enzymes participate in the synthesis and degradation of proteins, carbohydrates, fats, and nucleic acids. In addition, zinc releases vitamin $\mathrm{A}$, a potent antioxidant, from the liver and maintains constant levels in the blood [18]. Zinc constitutes a structural element of alkaline phosphatase (ALP). Zinc also stimulates ALP synthesis in osteoblasts and plays a role in bone mineralization [19]. In addition, it is responsible for the functions of metalloproteinases through a bond between zinc in the center of the enzyme and free $\mathrm{SH}$ group of cysteine present in the pro-peptide. The breaking of this bond and release of the pro-peptide can lead to the activation of metalloproteinases that are responsible for articular cartilage destruction in RA [20]. The reduction of zinc concentrations can result in growth retardation [21,22], decreased natural killer activity, and altered cytokine production. Zinc is important in the maintenance of proper immune function [21] by increasing cytokine generation via isolated leukocytes. It has a significant role in antioxidant processes because it is a constituent of superoxide dismutase (SOD) [23]. Zinc is involved in replication, transcription, and signal transduction treatment of wounds, glaucoma, RA, asthma, diabetes, stability of cellular membrane, structure and function of its antioxidant activity [24], hypothyroidism, and stress by enhancing the anti-oxidative activities of the 
body. The present study aimed to assess the association between serum levels of some TEs with the incidence of RA. This study was also conducted to investigate the relationship of certain TEs with other confounding factors, such as age and gender, and evaluate the correlation coefficient between all studied parameters. An alteration in the serum profile of the interested parameters was hypothesized because of the OS and inflammation are cooperative events involved with the incidence of RA. Therefore, these TEs acted as antioxidants and the serum levels of these TEs were altered because of the imbalance in the oxidative stress / antioxidant status, which favored OS.

\section{Patients and Methods}

This study was conducted to assess the association between the serum levels of specific TEs with the incidence of RA. This study was performed at Hawler Medical University, College of Pharmacy in period between 2013 and 2014.

\subsection{Study Design}

This case-control study involved 56 patients with RA of both genders. An equal number of apparently healthy adults randomly selected also participated in this study as the control group. The fasting blood $(10 \mathrm{cc})$ samples were drawn from the vein of the participants of both genders. The blood samples were left for 30 minutes for coagulation purpose, and then made centrifugation for 15 minutes at 2500-3500 revolution per minutes (rpm). The sera of the patients were separated and were divided into several parts and put them into several plastic plain tubes to do the biochemical tests of the current study. The sera of the patients were stored at ( -20 $\left.\mathrm{C}^{\circ}\right)$ till the day of the analysis within (1-4 months).All reagents and chemicals were of high analytical grade.

\subsection{Mothod}

Serum TEs were determined using flame and flameless atomic absorption spectrophotometry at the Ministry of Science and Technology /Department of Research of Biochemical Science, Baghdad city. The protocol of the study was approved by the Ethical Committee of College of Pharmacy. Verbal consent was obtained from all subjects before participation. Samples were collected under the guidance of an expert rheumatologist.

Exclusion criteria: None of the patients and controls were smokers or consumed alcohol or had any other chronic disease, except RA. Rheumatoid arthritis was confirmed by clinical examination and laboratory estimations of biochemical and hematological tests.

\subsection{Statistical Analysis}

SPSS 18.0 software was used for statistical analysis. Differences in various parameters between two groups were analyzed for significance using student's t-test and ANOVA. Statistical significance was defined as $\mathrm{p}<0.05$.

\section{Results}

The patient samples were divided into two groups, namely, rheumatoid factor (RF)-positive and RF-negative groups.

\subsection{The Effect of Rheumatoid Arthritis on the Serum Levels of Focused Parameters}

(Table 1) shows the comparison of RF-positive and RFnegative groups with the control group. Statistical analysis showed highly significant differences between the RFnegative group and control group regarding all the studied parameters $\mathrm{p}<0.001$. Moreover, highly significant differences were observed between the RF-positive group and control group regarding all the studied parameters $\mathrm{p}<$ 0.001 concerning $\mathrm{B}, \mathrm{Cu}, \mathrm{Ge}, \mathrm{Mg}, \mathrm{Se}$ and $\mathrm{Zn}$ and as well as regarding $\mathrm{Mg} \mathrm{p}=0.018$. A significant reduction in all studied parameters was observed within the patient groups.

Table 1. Comparison between patient groups ( $R F$ positive and $R F$ negative groups) with control group.

\begin{tabular}{llllll}
\hline & Control group Mean value ppm & Sample Mean value RF Negative & P value & Sample mean value RFPositive & P value \\
\hline $\mathrm{B}$ & 0.045 & 0.020 & $<0.001$ & 0.020 & $<0.001$ \\
$\mathrm{Cu}$ & 1.2 & 0.836 & $<0.001$ & 0.858 & $<0.001$ \\
$\mathrm{Ge}$ & 0.065 & 0.028 & $<0.001$ & 0.033 & $<0.001$ \\
$\mathrm{Mg}$ & 20 & 18.023 & $<0.001$ & 19.109 & 0.018 \\
$\mathrm{Se}$ & 0.101 & 0.050 & $<0.001$ & 0.043 & $<0.001$ \\
$\mathrm{Zn}$ & 1.2 & 0.660 & $<0.001$ & 0.690 & $<0.001$ \\
\hline
\end{tabular}

The comparison between RF-positive and RF-negative patient groups are presented in (Table 2). Significant differences were detected between the patient groups in terms of age $\mathrm{p}=0.05, \mathrm{Mg}$ level $\mathrm{p}=0.044$, and Se level $\mathrm{p}=0.044$.
By contrast, no significant differences were noted between the patient groups in terms of the levels of $\mathrm{B} \mathrm{p}=0.998, \mathrm{Cu} p$ $=0.601$, Ge $\mathrm{p}=0.433, \mathrm{Zn} \mathrm{p}=0.231$.

Table 2. Comparison between RF positive and negative patient groups regarding the interested parameters and age factor.

\begin{tabular}{|c|c|c|c|c|c|c|}
\hline & RF & $\mathbf{N}$ & Mean & \pm SD & SE & p value \\
\hline \multirow{2}{*}{ Age } & Positive & 28 & 46.64 & 4.824 & .912 & \multirow{2}{*}{.053} \\
\hline & Negative & 28 & 49.18 & 4.777 & .903 & \\
\hline \multirow{2}{*}{$\mathrm{Mg}$} & Positive & 28 & 19.109643 & 1.8647639 & .3524072 & \multirow{2}{*}{.044} \\
\hline & Negative & 28 & 18.023929 & 2.0698351 & .3911621 & \\
\hline
\end{tabular}




\begin{tabular}{|c|c|c|c|c|c|c|}
\hline & RF & $\mathbf{N}$ & Mean & \pm SD & SE & p value \\
\hline \multirow{2}{*}{$\mathrm{Cu}$} & Positive & 28 & .858571 & .1782988 & .0336953 & \multirow{2}{*}{.601} \\
\hline & Negative & 28 & .836071 & .1397177 & .0264042 & \\
\hline \multirow{2}{*}{$\mathrm{Zn}$} & Positive & 28 & .690250 & .1071806 & .0202552 & \multirow{2}{*}{.231} \\
\hline & Negative & 28 & .660000 & .0774597 & .0146385 & \\
\hline \multirow{2}{*}{$\mathrm{Se}$} & Positive & 28 & .043693 & .0076944 & .0014541 & \multirow{2}{*}{.004} \\
\hline & Negative & 28 & .050893 & .0100934 & .0019075 & \\
\hline \multirow{2}{*}{ B } & Positive & 28 & .020893 & .0093307 & .0017633 & \multirow{2}{*}{.998} \\
\hline & Negative & 28 & .020900 & .0078125 & .0014764 & \\
\hline \multirow{2}{*}{$\mathrm{Ge}$} & Positive & 28 & .033721 & .0366904 & .0069338 & \multirow[b]{2}{*}{.433} \\
\hline & Negative & 28 & .028214 & .0034141 & .0006452 & \\
\hline
\end{tabular}

\subsection{Age- Effect}

No significant age differences were observed in terms of the

The comparison between different age categories regarding the studied parameters are illustrated in (Table 3).

Table 3. The comparison between different age categories regarding the studied parameters.

\begin{tabular}{|c|c|c|c|c|c|}
\hline & Age & $\mathbf{N}$ & Mean & SD & p \\
\hline \multirow{5}{*}{$\mathrm{Mg}$} & $40-44$ & 17 & 19.518 & 2.220 & \multirow{5}{*}{.108} \\
\hline & $45-49$ & 12 & 18.522 & 2.498 & \\
\hline & $50-54$ & 19 & 18.048 & 1.284 & \\
\hline & $55+$ & 8 & 17.841 & 1.8 & \\
\hline & Total & 56 & 18.5668 & 2.027 & \\
\hline \multirow{5}{*}{$\mathrm{Cu}$} & $40-44$ & 17 & .8229 & .1757 & \multirow{5}{*}{.767} \\
\hline & $45-49$ & 12 & .8817 & .1631 & \\
\hline & $50-54$ & 19 & .8568 & .1390 & \\
\hline & $55+$ & 8 & .8250 & .1806 & \\
\hline & Total & 56 & .8473 & .1591 & \\
\hline \multirow{5}{*}{$\mathrm{Zn}$} & $40-44$ & 17 & .7045 & .1175 & \multirow{5}{*}{.489} \\
\hline & $45-49$ & 12 & .6592 & .0871 & \\
\hline & $50-54$ & 19 & .6668 & .0772 & \\
\hline & $55+$ & 8 & .6563 & .0857 & \\
\hline & Total & 56 & .6751 & .0939 & \\
\hline \multirow{5}{*}{$\mathrm{Se}$} & $40-44$ & 17 & .0446 & .0071 & \multirow{5}{*}{.403} \\
\hline & $45-49$ & 12 & .0462 & .0083 & \\
\hline & $50-54$ & 19 & .0498 & .0117 & \\
\hline & $55+$ & 8 & .0486 & .0106 & \\
\hline & Total & 56 & .0474 & .0096 & \\
\hline \multirow{5}{*}{ B } & $40-44$ & 17 & .0218 & .0082 & \multirow{5}{*}{.205} \\
\hline & $45-49$ & 12 & .0248 & .0064 & \\
\hline & $50-54$ & 19 & .0188 & .0098 & \\
\hline & $55+$ & 8 & .0181 & .0077 & \\
\hline & Total & 56 & .0209 & .0085 & \\
\hline \multirow{5}{*}{$\mathrm{Ge}$} & $40-44$ & 17 & .0269 & .0036 & \multirow{5}{*}{.383} \\
\hline & $45-49$ & 12 & .0425 & .0560 & \\
\hline & $50-54$ & 19 & .0292 & .0031 & \\
\hline & $55+$ & 8 & .0264 & .0043 & \\
\hline & Total & 56 & .0310 & .0260 & \\
\hline
\end{tabular}

\subsection{Gender-Effect}

The comparison between men and women in patient group was shown in (Table 4). Significant differences were detected between men and women regarding the levels of $\mathrm{B} p<0.001$,
$\mathrm{Cu} \mathrm{p}=0.009, \mathrm{Mg} \mathrm{p}=0.037$ and Se $\mathrm{p}<0.001$. By contrast, no significant differences were noted between men and women regarding the levels of $\mathrm{Ge} \mathrm{p}=0.262$ and $\mathrm{Zn} \mathrm{p}=$ 0.212 . 
Table 4. Comparison between men and women regarding the interested parameters.

\begin{tabular}{lllllll}
\hline & Sex & N & Mean & SD & SE & p value \\
\hline \multirow{2}{*}{$\mathrm{Mg}$} & Women & 24 & 17.9171 & 1.9126 & .3904 & .037 \\
& Men & 32 & 19.0541 & 2.0016 & .3538 & .0189 \\
$\mathrm{Cu}$ & Women & 24 & .7846 & .0928 & .0189 & \\
& Men & 32 & .8944 & .1822 & .0322 & .212 \\
$\mathrm{Zn}$ & Women & 24 & .6579 & .0708 & .0144 & \\
& Men & 32 & .6880 & .1074 & .0190 & \\
$\mathrm{Se}$ & Women & 24 & .0523 & .0082 & .0017 & \\
& Men & 32 & .0436 & .0090 & .0016 & \\
$\mathrm{~B}$ & Women & 24 & .0265 & .0047 & .0010 & .0010 \\
& Men & 32 & .0167 & .0084 & .0015 & .0080 \\
$\mathrm{Ge}$ & Women & 24 & .0363 & .0392 & .0007 & .262 \\
\hline
\end{tabular}

\subsection{Correlation Coefficient}

The correlation coefficient between all the studied parameters and age factor in the patient groups are presented in (Table 5). A medium significantly positive correlation between $\mathrm{Mg}$ and copper was observed $\mathrm{p}=0.01, \mathrm{r}=0.419$. A medium significantly negative correlation between $\mathrm{Mg}$ and
Se was found $\mathrm{p}=0.01, \mathrm{r}=-0.441$. A weak significantly negative correlation between $\mathrm{Mg}$ and age was noted $\mathrm{p}=0.01$, $\mathrm{r}=-0.376$. A medium negative correlation between $\mathrm{Cu}$ and Se was detected $\mathrm{p}=0.01, \mathrm{r}=-0.486$. A weak negative correlation between $\mathrm{Cu}$ and $\mathrm{B}$ was observed $\mathrm{p}=0.5, \mathrm{r}=$ -0.271 . A weak positive correlation between Se and B was revealed $\mathrm{p}=0.5, \mathrm{r}=0.301$.

Table 5. The correlation coefficient between all the interested parameters and age factor.

\begin{tabular}{|c|c|c|c|c|c|c|c|c|c|}
\hline & & Mg & $\mathbf{C u}$ & $\mathbf{Z n}$ & Se & B & Ge & Age & \\
\hline \multirow{3}{*}{$\mathrm{Mg}$} & Pearson Corr & \multirow{3}{*}{$\begin{array}{l}1 \\
56\end{array}$} & $.419 * *$ & .231 & $-.441 * *$ & -.145 & -.206 & $-.376^{* *}$ & $\mathrm{r}$ \\
\hline & Sig(2-tailed) & & 0.01 & .087 & .001 & .285 & .127 & .004 & $P$ \\
\hline & $\mathrm{N}$ & & 56 & 56 & 56 & 56 & 56 & 56 & $\mathrm{~N}$ \\
\hline \multirow{3}{*}{$\mathrm{Cu}$} & Pearson Corr & $.419 * *$ & 1 & .042 & $-.484 * *$ & $-.271 *$ & -.243 & -.031 & \\
\hline & Sig(2-tailed) & .001 & & .760 & .000 & .044 & .071 & .821 & \\
\hline & $\mathrm{N}$ & 56 & 56 & 56 & 56 & 56 & 56 & 56 & \\
\hline \multirow{3}{*}{$\mathrm{Zn}$} & Pearson Corr & .231 & .042 & 1 & -.209 & -.049 & -.179 & -.159 & \\
\hline & Sig(2-tailed) & .087 & .760 & & .123 & .720 & .188 & .241 & \\
\hline & $\mathrm{N}$ & 56 & 56 & 56 & 56 & 56 & 56 & 56 & \\
\hline \multirow{3}{*}{$\mathrm{Se}$} & Pearson Corr & $-.441 * *$ & $-.484 * *$ & -.209 & 1 & $.301 *$ & .221 & .211 & \\
\hline & Sig(2-tailed) & .001 & .000 & .123 & & .024 & .102 & .118 & \\
\hline & $\mathrm{N}$ & 56 & 56 & 56 & 56 & 56 & 56 & 56 & \\
\hline \multirow{3}{*}{ B } & Pearson Corr & -.145 & $-.271 *$ & -.049 & $.301 *$ & 1 & .062 & -.107 & \\
\hline & Sig(2-tailed) & .285 & .044 & .720 & .024 & & .650 & .434 & \\
\hline & $\mathrm{N}$ & 56 & 56 & 56 & 56 & 56 & 56 & 56 & \\
\hline \multirow{3}{*}{$\mathrm{Ge}$} & Pearson Corr & -.206 & & -.179 & .221 & .062 & 1 & .020 & \\
\hline & Sig(2-tailed) & .127 & & .188 & .102 & .650 & & .882 & \\
\hline & $\mathrm{N}$ & 56 & & 56 & 56 & 56 & 56 & 56 & \\
\hline \multirow{3}{*}{ Age } & Pearson Corr & $-.376 * *$ & -.031 & -.159 & .211 & -.107 & .020 & & \\
\hline & $\operatorname{Sig}(2$-tailed) & .004 & .821 & .241 & .118 & .434 & .882 & $\begin{array}{l}1 \\
56\end{array}$ & \\
\hline & $\mathrm{N}$ & 56 & 56 & 56 & 56 & 56 & 56 & 50 & \\
\hline
\end{tabular}

\section{Discussion}

\subsection{General View}

This study aimed to assess the association between the serum levels of certain TEs in Iraqi patients with incidence of $\mathrm{RA}$, and investigate their relationship with other confounding factors such as type of rheumatoid arthritis (rheumatoid arthritis with rheumatoid factor positive or negative), age, gender. Moreover, the correlation coefficient between all the studied parameters was also evaluated.

\subsection{The Effect of Rheumatoid Arthritis on the Serum Levels of Focused Parameters}

(Table 1) presents the comparison between the patient groups with the control group.

\subsubsection{The Effect of Rheumatoid Arthritis on the Serum Boron Levels}

The level of boron in the patient groups (RF-positive and RF-negative groups) significantly decreased compared with that in the control group $p<0.001$. However, limited data are available regarding the relation of boron level to RA patients. 
The results of the current study were consistent with previous result regarding the RF-positive group [25]. Accordingly, the present study is the first to deal with the association of boron with RA (RF-negative group). The daily intake of boron was $1 \mathrm{mg}$, and the incidence of arthritis ranged from $20 \%$ to $70 \%$. In other areas where the daily intake of boron ranged from 3 $\mathrm{mg}$ to $>10 \mathrm{mg}$, the incidence of arthritis ranged from $0 \%$ to $10 \%$. A recent studies with mild, moderate, or severe osteoarthritis showed that boron supplementation alleviates subjective measures of arthritis [26].

\subsubsection{The Effect of Rheumatoid Arthritis on the Serum Copper Levels}

Copper has an important role in the functions of many enzymes, and its deficiency can cause dysfunction of antioxidant enzymes peroxidase and catalase [27]. The level of copper significantly decreased in the patient groups (RFpositive and RF-negative groups) compared with that in the control group $\mathrm{p}<0.001$, (Table 1).

The results of this study were in agreement with those of previous studies $[16,28-30]$. The significant reduction in $\mathrm{Cu}$ might be due to the increased utilization of $\mathrm{Cu}$ for the synthesis and activation of the antioxidant enzyme SOD as a defense mechanism. A previous study reported that significantly decreased levels of $\mathrm{Cu}$ in RBCs of RA patients [30] might be due to the increased utilization of $\mathrm{Cu}$ in RBCs, because of increased activation of SOD as a defense mechanism. Low levels of $\mathrm{Cu}$ in erythrocytes may suggest lower SOD activity, which may lead to some abnormalities in neutralizing oxygen free radicals. SOD is one of the first enzymes that loses its activity in the case of decreased access of $\mathrm{Cu}[13]$.

\subsubsection{The Effect of Rheumatoid Arthritis on the Serum Germanium Levels}

The level of germanium significantly decreased in the patient groups (RF-positive and RF-negative groups) as compared with the control group $p<0.001$, (Table 1). Some people use germanium for osteoarthritis, osteoporosis, and pain relief. Germanium can also alleviate RA symptoms and normalize physiological functions.

The results of this study were in accordance with a previous study [30]. The significant reduction in Ge level was due to the fact that Ge acts as an antioxidant element, which increased its utilization to neutralize the free radicals in RA. Germanium acts against inflammation and affects the immune system.

\subsubsection{The Effect of Rheumatoid Arthritis on the Serum Magnesium Levels}

Magnesium maintains the equilibrium of extracellular magnesium in bones and soft tissues. The obtained results show that magnesium significantly decreased in patients with RA. As shown in (Table 1), the level of magnesium significantly decreased in the RF-positive $p=0.018$ and RFnegative groups $\mathrm{p}<0.001$. This result was in accordance with that of previous studies [31, 32].

\subsubsection{The Effect of Rheumatoid Arthritis on the Serum Selenium Levels}

Selenium is an antioxidant and main constituent of the antioxidant enzyme glutathione peroxidase. The result of this study was in agreement with those of previous studies [30, 33-35]. These results reveal that the reduction in Se levels was a result of a defense mechanism against inflammation and OS that occurred with RA. The current finding, as well as that from another study [34], proves the possible association between decreased levels of serum Se with RA. Researchers explained that the decreased levels of Se are possibly attributed to redistribution from the plasma into the tissues as a defense mechanism against inflammation.

\subsubsection{The Effect of Rheumatoid Arthritis on the Serum Zinc Levels}

The level of $\mathrm{Zn}$ significantly decreased in the RF-positive and RF-negative groups as compared with the control group $\mathrm{p}$ $<0.001$, (Table 1). The result of this study was in agreement with those of previous studies $[16,29-31,33-36]$. The significant reduction in $\mathrm{Zn}$ level was due to the fact that $\mathrm{Zn}$ was highly utilized because it is an antioxidant and as a constituent of the antioxidant enzyme structure SOD. Moreover, $\mathrm{Zn}$ acts as a defense mechanism against inflammation. This finding shows that the development of inflammation and OS in RA induced an increase in the body's requirement for $\mathrm{Zn}$. In addition, pro-inflammatory cytokines IL-1 and TNF- $\alpha$, which are associated with the pathogenesis of RA [37], inhibit the synthesis of albumins in the liver and decrease their zinc-binding capacity, thereby leading to lower levels of plasma $\mathrm{Zn}$ [18] . The reduction in serum $\mathrm{Zn}$ levels may be related to the synthesis of metallothionein in liver and other tissues. Metallothionein binds with $7 \mathrm{~g}$ atoms of $\mathrm{Zn}$ per mole, and it is stimulated by IL-1 [38]. The accumulation of $\mathrm{Zn}$ in metallothionein, inflamed joints, and many other organs during inflammation possibly requires more $\mathrm{Zn}$ to activate other unidentified metalloenzymes that are necessary for the stress conditions leading to hypozincemia in RA. The comparison between RF-positive and RF-negative groups was shown in (Table 2). Significant differences were observed between these two groups in terms of the mean serum levels of $\mathrm{Mg}$ and Se $\mathrm{p}<0.05$, but no significant differences were found between these two groups regarding the levels of $\mathrm{B}, \mathrm{Cu}, \mathrm{Ge}$ and $\mathrm{Zn}, \mathrm{p}>0.05$.

These results are the first attempt to deal with comparison between RF-positive group and RF-negative group regarding the studied parameters.

\subsection{Age-Effect}

In this study, the mean ages in the RF-positive group and RF-negative group were $46.64 \pm 4.824$ and $49.18 \pm 4.777$ years, respectively (Table 2).

The ages of patients ranged from 40 years to 57 years (Table 1). The onset of RA occurs at all ages [39], but the incidence is highest between the ages of 35 and 50 years [40]. A previous study reported that the average age of RA patients is 42 years, but the amount of patients in the 50-60 year age 
range is higher than that in the other age ranges [29]. In the present study, the highest incidence of RA occurred between the ages of 50 and 54 years (Table 3), which was in accordance with previous findings [29, 40]. A previous study reported that the age groups show no significant age differences in terms of $\mathrm{Zn}$ and $\mathrm{Cu}$ levels [29]. Moreover, [41] reported no age dependence in zinc values. The results of the current study were consistent with previous findings regarding $\mathrm{Cu}$ [29] and $\mathrm{Zn}[29,41]$. (Table 3) reveals the absence of significant age differences in terms of the levels of $\mathrm{B}, \mathrm{Cu}, \mathrm{Ge}, \mathrm{Mg}$, Se, and $\mathrm{Zn}$.

\subsection{Gender-Effect}

The comparison between men and women was present in (Table 4). Significant differences were found between men and women regarding the levels of $\mathrm{B} \mathrm{p}<0.001, \mathrm{Cu} \mathrm{p}=0.009, \mathrm{Mg}$ $\mathrm{p}=0.037$ and Se $\mathrm{p}<0.001$. By contrast, no significant differences were observed between men and women regarding the levels of Ge and $\mathrm{Zn}$. These significant differences might be possibly related to specific female hormones, which are one of the predisposing factors of this disease, or autoimmune diseases in this genus [43]. However, a previous study [30] reported no significant variations in the levels of $\mathrm{Cu}, \mathrm{Ge}, \mathrm{Se}$, and $\mathrm{Zn}$ in relation to gender. The results of another study showed that groups do not exhibit significant gender variation in terms of the levels of zinc and copper [29]. Variations in the levels of TEs, which are a part of the immune system, are induced by the pro-inflammatory cytokines IL-1, TNF- $\alpha$, and IL-6. These substances are immunocytokines liberated mostly by activated macrophages in response to several stimuli, including exercise, trauma, stress, or infection [43].

\subsection{Correlation Coefficient}

The correlation coefficient between all the investigated parameters and age factor in the patient groups was revealed in (Table 5). A medium significantly positive correlation between $\mathrm{Mg}$ and copper was observed $\mathrm{p}=0.01, \mathrm{r}=0.419$. A medium significantly negative correlation between $\mathrm{Mg}$ and Se was noted $\mathrm{p}=0.01, \mathrm{r}=-0.441$. A weak significantly negative correlation between $\mathrm{Mg}$ and age was found $\mathrm{p}=0.01$, $\mathrm{r}=-0.376$. A medium negative correlation between $\mathrm{Cu}$ and Se was detected $\mathrm{p}=0.01, \mathrm{r}=-0.486$. A weak negative correlation between $\mathrm{Cu}$ and $\mathrm{B}$ was revealed $\mathrm{p}=0.5, \mathrm{r}=$ -0.271 . A weak positive correlation between Se and B was discovered $\mathrm{p}=0.5, \mathrm{r}=0.301$.

These results allow physicians to correct these imbalances of TEs in serum levels to improve the pathological status of patients. This study has points of strength, such as strict inclusion and exclusion criteria, and defined data measurement and collection. The results of the present study were in line with the hypothesis that low antioxidant TE levels are a risk factor for RA.

\section{Conclusion}

The serum levels of studied parameters were significantly decreased in patients with RA compared with those in the control group. These variations were probably responses to inflammation, and may be a part of the cytokine-induced autoimmune process in patients. These variations also possibly resulted from the defense mechanism of patients. The results of this study indicate that certain TEs might play a role in the pathophysiology of RA. Given the significant reduction in serum levels of these parameters, supplementation with TEs could be necessary for RA therapy, and even more important to individuals who are at high risk of developing RA. The deficiency of these TEs could be used as complementary noninvasive parameters for early diagnosis and treatment of RA. The variation in TEs in sera of patients with RA may shed more light on the role of TEs in physiological and pathological conditions. These findings prove the possible association between decreased levels of certain parameters with RA. Significant differences between RF-positive and RF-negative groups were observed regarding the levels of $\mathrm{Mg}$ and $\mathrm{Se}(\mathrm{p}<$ 0.05 ), but no significant differences were noted between these two groups regarding the levels of $\mathrm{B}, \mathrm{Cu}, \mathrm{Ge}, \mathrm{Zn} \mathrm{p}>0.05$. Rheumatoid factor was an independent significant predictor of decreased serum levels of the investigated parameters in the RF-positive group. The present study demonstrated that RA was characterized by increased levels of RF, which is a marker of inflammation. This finding proves the involvement of inflammation with the incidence of RA. No significant age differences regarding the investigated parameters were observed. Moreover, significant differences were observed between men and women regarding the levels of $\mathrm{B}, \mathrm{Cu}, \mathrm{Mg}$ and Se. By contrast, no significant differences were observed between men and women regarding the levels of Ge and $\mathrm{Zn}$.

Further investigations are necessary to study the activities of immunocytokines, trace metals, and antioxidant enzymes.

\section{Abbreviation}

IL-1: interleukin-1, FRs: Free radicals, OS: Oxidative stress, RA: Rheumatoid arthritis, SOD: superoxide dismutase, TEs: Trace elements, TNF- $\alpha$ : Tumor necrosis factor.

\section{References}

[1] Michael LB, Edward PF and Larry GS. (2010). Clinical Chemistry Lippincott William and Wilkins: 403-668.

[2] Ozkan Y, Yardym-Akaydyn S, Sepici A, Keskin E, Sepici V, Simsek B. (2006). Oxidative status in rheumatoid arthritis. Clin Rheumatol, 25: (Epub ahead of print).

[3] Pasha Q, Malik SA, Shaheen N, Shah MH. (2010). Investigation of trace metals in the blood plasma and scalp hair of gastrointestinal cancer patients in comparison with controls. Clin Chim Acta, 411: 531-539.

[4] Hitchon CA, Gabalawy HS EL. (2004). Oxidation in rheumatoid arthritis. Arthritis Res.Ther, 6: 265-278.

[5] Ostrakhovitch EA, Afanas'ev IB. (2001). Oxidative stress in rheumatoid arthritis leukocytes: suppression by rutin and other antioxidants and chelators. Biochem. Pharmacol, 62: 743-746. 
[6] Lovell DJ, Glass D, Ranz J, Kramer S, Huang B, Sierra RI, Henderson CJ, Passo M, Graham B, Bowyer S, Higgins G, Rennebohm R, Schikler KN, Giannini E.(2006). A randomized controlled trial of calcium supplementation to increase bone mineral density in children with juvenile rheumatoid arthritis. Arthrit Rheum, 54: 2235-2242.

[7] Hunt CD.(2003). Dietary boron: an overview of the evidence for its role in immune function. J Trace Elem Exp Med, 16: 291-306.

[8] Devirian TA, Volpe SL. (2003). The physiological effects of dietary boron. Crit Rev Food Sci Nutr, 43 : 219-231.

[9] Sutherland B, Strong P, King JC. (1998). Determining human dietary requirements for boron. Biol Trace Elem Res, 66: 193204.

[10] Hunt CD, Idso JP.(1999). Dietary boron as a physiological regulator of the normal inflammatory response: a review and current research progress. J Trace Elem Exp Med, 12: 221-233.

[11] Benderdour M, Hess K, Dzondo-Gadet M, Nabet P, Belleville F, Dousset B. (1998). Boron modulates extracellular matrix and TNFa synthesis in human fibroblasts. Biochem Biophys Res Commun, 246: 746-751.

[12] Nielsen F.H. (2008). "Is boron nutritionally relevant?," Nutr. Rev, 66: 183-191.

[13] Tapiero H, Townsend DM, Tew KD. (2003). Trace elements in human physiology and phatology. Copper. Biomed Pharmacother, 57(9): 386-398.

[14] Kagan HM, Li W. (2003). Lysyl oxidase properties, specifity, and biological roles inside and outside of the cell. J Cell Biochem, 88(4): 660-672.

[15] Hathcock JN. (2004). Vitamins and minerals safety . 2nd ed. : $35-49$.

[16] Satish KT and Reshu M. (2009). Assessment of mineral status $(\mathrm{Zn}, \mathrm{Cu}, \mathrm{Mg}$ and $\mathrm{Mn}$ ) in Rheumatoid Arthritis patients in Chandigarh, India. Rheumatology Report, 1(5): 16-20.

[17] Hoffmann PR, Berry MJ. (2008). The influence of selenium on immune responses. Mol Nutr Food Res, 52(11): 1273-1280.

[18] Tapiero H, Tew KD. (2003). Trace elements in human physiology and pathology: Zinc and metallothioneins. Biomed Pharmacother, 57: 399-411.

[19] Heath DA, Shaw NJ. (2001). Calcium and bone metabolism. In: Brook C, Hindmarsh P, editors. Clinical pediatric endocrinology. 4. Oxford: Blackwell Science : 377-389.

[20] Wong P., Cuello C., Bertouch JV., Robert-Thaomson PJ. , Ahern MJ. , Smith MD. and Youssef PP. (2000). The effects of pulse methylprednisolone on matrix metalloproteinase and tissue inhibitor of metalloproteinase-1 expression in rheumatoid arthritis. Rheumatology, 39 : 1067-1073.

[21] Rink L and Haase H. (2006). Zinc homeostasis and immunity. trends in immunology, 28 (1): 1-4.

[22] Florianczyk B. (2008). Trace elements as constituents of antioxidative proteins. Journal of pre-clinical and clinical research, 2(1): 25-27.

[23] Honkanen V. (1991). The factors affecting plasma glutathione peroxidase and selenium in rheumatoid arthritis: A multiple linear regression analysis. Scand J, 20: 385-391.
[24] Hennig, B., M. Toborek and C.J. Mcclain, (1996). Antiatherogenic properties of zinc: Implications in endothelial cell metabolism. Nutrition, 12: 711-717.

[25] Ziad S. Al-Rawi, Faiq I. Gorial, Wejdi A. Al-Shammary, Fadhil Muhsin, Ahmed S. Al-Naaimi, Sa'ad Kareem, (2013). Serum boron concentration in rheumatoid arthritis: correlation with disease activity, functional class, and rheumatoid factor. J Exp Integr Med, 3(1): 9-15.

[26] Miljkovic D, Scorei RI, Cimpoiasu VM, Scorei ID. (2009). Calcium fructoborate : plant-based dietary boron for human nutrition. J Diet Suppl, 6(1): 211-226.

[27] Mazzetti, I., B. Grigolo, R.M. Borz , R. Meliconi, A. Facchini, (1996). Serum copper/zinc superoxide dismutase levels in patients with rheumatoid arthritis. Int. J. clin. Lab. Res, 26: 245-249.

[28] Tuncer S, Kamanli A, Akcil E, Kavas GO, Seckin B, Atay MB (1999). Trace element and magnesium levels and superoxide dismutase activity in rheumatoid arthritis. Biol Trace Elem Res, 68(2): 137-142.

[29] Ala S, shokrzadeh M, Pur shoja AM and Saravi SSS. (2009). Zinc and Copper plasma concentrations in Rheumatoid Arthritis patients from a selected population in Iran . Pakistan Journal of biological sciences, 12 (14): 1041-1044.

[30] Huda M. Ali and Mohammed A. Al-Zubaidi, (2012). Evaluation of Trace Elements in Iraqi Patients with Rheumatoid Arthritis by using Atomic Absorption Spectrophotometer . Iraqi J Pharm Sci, 21(2 ): 77-84.

[31] Taneja SK, Mandal R. (2009). Assessment of mineral status $(\mathrm{Zn}, \mathrm{Cu}, \mathrm{Mg}$ and $\mathrm{Mn}$ ) in rheumatoid arthritis patients in Chandigarh, India. Rheumatology Reports, 1(5): 16-20.

[32] Rana A. Alaly, Ahmed A. Abdulsahib, Saba S. Mohsen, Zainab Abbas Jwad, (2012). The Relation of Serum sodium ,Potassium and Magnessium with Rheumatoid Anthritis Symptom. Medical Journal of Babylon, 9(4): 912917.

[33] De-Lorgeril M., Salen P., Accominotti M., Cadau M., Steghens J.P., Boucher F. (2001). Dietary and blood antioxidants in patients with chronic heart failure. Insights into the potential importance of selenium in heart failure. Eur. J. Heart. Fail, 3: 661-669.

[34] Colak M, Bingol NK, Ayhan O and Avci S. (2001). Serum Copper, Zinc and Selenium levels in Rheumatoid Arthritis. Rhomatizma, 16(2): 66-71.

[35] Topuzoglu, G., A.R. Erbay, A.B. Karul and N. Yensel, (2003). Concentrations of copper, zinc and magnesium in sera from patients with idiopathic dilated cardiomyopathy. Biol. Trace. Elem. Res, 95: 7-11.

[36] Carl AB and Edward RA. (2008). "Tietz Fundamentals of Clinical Chemistry", 6th Ed., Saunders an imprint of Elsevier : 496-507.

[37] Yazar M, Sarban S, Kocyigit A, Isikan UE. (2005). Synovial fluid and plasma selenium, copper, zinc, and iron concentrations in patients with rheumatoid arthritis and osteoarthritis. Biol Trace Elem Res, 106: 123-132.

[38] Rofe AM, Philcox JC, Coyle P. (1996). Trace metal, acute phase and metabolic response to endotoxin in metallothioneinnull mice. Biochem J, 314: 793-797. 
[39] Krishna Mohan Surapneni and V S Chandrasada Gopan, (2008). Lipid Peroxidation and Antioxidant Status in Patients with Rhumatoid Anthritis. Indian Journal of Clinical Biochemistry, 23(1): 41-44.

[40] Prakash B. Desai S. Manjunath Sumangalakadi K. Chetana J.Vanishree, (2010). Oxidative stress and enzymatic antioxidant status in rheumatoid arthritis: a case control study. European Review for Medical and Pharmacological Sciences, $14: 959-967$.

[41] Helena Mussalo- Rauhamaa, Yrjo T. Konttinen, Jari Letho and Visa Honkanen, (1988). Predictive clinical and laboratory parameters for serum zinc and copper in rheumatoid arthritis. Annals of the Rheumatic Diseases, 47 : 816-819.
[42] Kelly. Kelly's Textbook of Rheumatology. 6th Edn., Vol. 1, Sanders Company USA., 2001: 321-324.

[43] Mastousek AJ, Burguera JL, Burguera M, Anez N. (1993). Changes in total content of iron, copper and zinc in serum, heart, liver, spleen and skeletal muscle tissues of rats infected with Trypanosoma cruzi. Biol Trace Elem Res, 37: 51-69. 